Supplement of The Cryosphere, 16, 349-378, 2022 https://doi.org/10.5194/tc-16-349-2022-supplement (c) Author(s) 2022. CC BY 4.0 License.

(c) (1)

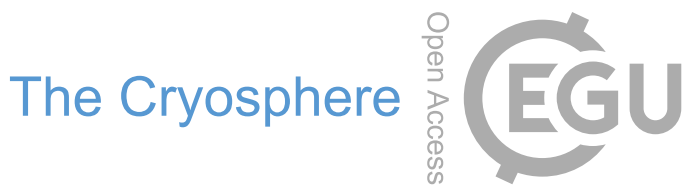

Supplement of

\title{
Satellite passive microwave sea-ice concentration data set intercompari- son using Landsat data
}

\section{Stefan Kern et al.}

Correspondence to: Stefan Kern (stefan.kern@uni-hamburg.de)

The copyright of individual parts of the supplement might differ from the article licence. 


\section{Supplementary Material}

Table S1. List of dates of Landsat- 5 and Landsat- 8 scenes used in the respective ice regimes in both hemispheres. If there is more than one scene used per day, the date has an ' $a$ ', ' $b$ ', and so forth appended. Listed are only those scenes that fit adequately into our definition of ice regimes. Note there is overlap between regime 'melt conditions' and other regimes.

\begin{tabular}{|c|c|c|c|c|c|c|}
\hline & \multicolumn{2}{|c|}{ Landsat-5, NH } & \multicolumn{2}{|c|}{ Landsat- $8, \mathrm{NH}$} & \multicolumn{2}{|l|}{ Landsat- $8, \mathrm{SH}$} \\
\hline Freeze-up & None & & $\begin{array}{l}20140918, \\
20150915\end{array}$ & 20150914, & $\begin{array}{l}20140216, \\
20140227 \mathrm{a}, \\
20140305, \\
20140312 \mathrm{a}, \\
20150312 \mathrm{a}, \\
20150321\end{array}$ & $\begin{array}{r}20140223, \\
20140227 \mathrm{~b}, \\
20140307, \\
20140312 \mathrm{~b}, \\
20150312 \mathrm{~b},\end{array}$ \\
\hline \# cases & 0 & & 3 & & 11 & \\
\hline Ice edge & None & & $\begin{array}{l}20130427 a, \\
20130527, \\
20150405,20\end{array}$ & $\begin{array}{l}20130427 b, \\
20150316, \\
50419\end{array}$ & $\begin{array}{l}20131130, \\
20140114, \\
20140216, \\
20141222,20\end{array}$ & $\begin{array}{r}20131228, \\
20140115, \\
20140227, \\
41224\end{array}$ \\
\hline \# cases & 0 & & 6 & & 8 & \\
\hline Leads / Openings & $\begin{array}{l}20030407, \\
20050410, \\
20050414 \mathrm{~b}, \\
20050423, \\
20060402, \\
20060408, \\
20060426, \\
20060430, \\
20070409, \\
20070412 \mathrm{~b}, \\
20080321, \\
20080409, \\
20080423 \mathrm{~b}, \\
20090418, \\
20090524, \\
20100527\end{array}$ & $\begin{array}{r}20050408, \\
20050414 \mathrm{a}, \\
20050419, \\
20050521, \\
20060404, \\
20060421, \\
20060427, \\
20070407, \\
20070412 \mathrm{a}, \\
20070415, \\
20080407, \\
20080423 \mathrm{a}, \\
20090320, \\
20090426, \\
20100510,\end{array}$ & $\begin{array}{l}20130425, \\
20130529, \\
20140326, \\
20140402, \\
20140428, \\
20150404, \\
20150407, \\
20150414 \mathrm{a}, \\
20150414 \mathrm{c}, \\
20150422, \\
20150423 \mathrm{~b}, \\
20150425 \mathrm{a}, \\
20150427, \\
20150514, \\
20150524,20\end{array}$ & $\begin{array}{c}20130501, \\
20140321, \\
20140330, \\
20140416, \\
20150401, \\
20150406, \\
20150413, \\
20150414 b, \\
20150416, \\
20150423 \mathrm{a}, \\
20150423 \mathrm{c}, \\
20150425 \mathrm{~b}, \\
20150428, \\
20150516, \\
50528\end{array}$ & $\begin{array}{l}20131105, \\
20131117, \\
20131208, \\
20131221, \\
20140102, \\
20140215, \\
20140227, \\
20140312, \\
20141030, \\
20141220, \\
20151005 \mathrm{a}, \\
20151021, \\
20151023 \mathrm{~b}, \\
20151202, \\
20151213\end{array}$ & $\begin{array}{r}20131109, \\
20131118, \\
20131214, \\
20131227, \\
20140203, \\
20140223, \\
20140307, \\
20141024, \\
20141201, \\
20151002, \\
20151005 b, \\
20151023 a, \\
20151123, \\
20151212,\end{array}$ \\
\hline \# cases & 31 & & 30 & & 29 & \\
\hline Heterogeneous ice & $\begin{array}{l}20050424, \\
20050524 \mathrm{~b}, \\
20090321, \\
20090416, \\
20100510, \\
20100524 \mathrm{~b}\end{array}$ & $\begin{array}{r}20050524 \mathrm{a}, \\
20080511, \\
20090403, \\
20090528, \\
20100524 \mathrm{a},\end{array}$ & $\begin{array}{l}20130422, \\
20140503 \mathrm{~b}, \\
20140517 \mathrm{~b}, \\
20150420, \\
20150425 \mathrm{~b}, \\
20150427, \\
20150516 \mathrm{~b}, \\
20150519 \mathrm{~b}, \\
20150522 \mathrm{~b}\end{array}$ & $\begin{array}{r}20140503 a, \\
20140517 a, \\
20150419, \\
20150425 a, \\
20150425 \mathrm{c}, \\
20150516 a, \\
20150519 a, \\
20150522 a,\end{array}$ & $\begin{array}{l}20131103, \\
20131111 \mathrm{a}, \\
20131111 \mathrm{c}, \\
20131208 \mathrm{~b}, \\
20131210 \mathrm{~b}, \\
20140101, \\
20140114 \mathrm{~b}, \\
20140129, \\
20141009, \\
20141031, \\
20141203, \\
20141210, \\
20141226, \\
20151001, \\
20151111, \\
20151128, \\
20151212\end{array}$ & $\begin{array}{r}20131108, \\
20131111 \mathrm{~b}, \\
20131208 \mathrm{a}, \\
20131210 \mathrm{a}, \\
20131212, \\
20140114 \mathrm{a}, \\
20140118, \\
20140305, \\
20141028, \\
20141101, \\
20141205, \\
20141224, \\
20150312, \\
20151022, \\
20151120, \\
20151130,\end{array}$ \\
\hline \# cases & 11 & & 17 & & 33 & \\
\hline
\end{tabular}


Table S1, continued.

\begin{tabular}{|c|c|c|c|}
\hline & Landsat-5, NH & Landsat- $8, \mathrm{NH}$ & Landsat-8, SH \\
\hline High-concentration & 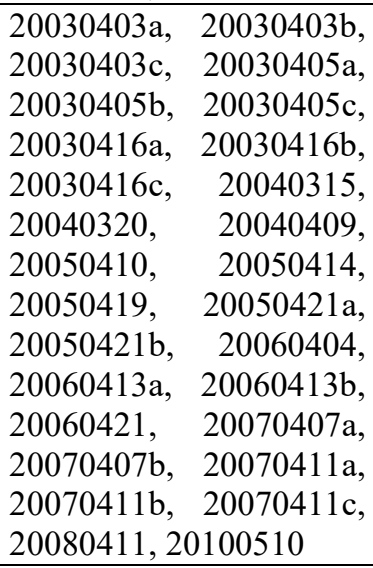 & $\begin{array}{lr}20140405, & 20150404, \\
20150411 \mathrm{a}, & 20150411 \mathrm{~b}, \\
20150412, & 20150416 \mathrm{a}, \\
20150416 \mathrm{~b}, & 20150418, \\
20150420 \mathrm{a}, & 20150420 \mathrm{~b}, \\
20150420 \mathrm{c}, 20150420 \mathrm{~d}\end{array}$ & $\begin{array}{l}20131110,20131208, \\
20150312,20151104\end{array}$ \\
\hline \# cases & 28 & 12 & 4 \\
\hline Melt conditions & $\begin{array}{lr}20030516, & 20040518, \\
20040522, & 20050521, \\
20050524 \mathrm{a}, & 20050524 \mathrm{~b}, \\
20060528, & 20080520, \\
20090524, & 20090528, \\
20100524 \mathrm{a}, & 20100524 \mathrm{~b}, \\
20100527 & \end{array}$ & $\begin{array}{l}20130527, \\
20140517 \mathrm{a}, \\
20150516 \mathrm{a}, \\
20150516 \mathrm{c}, \\
20150519 \mathrm{~b}, \\
20150522 \mathrm{~b}, \\
20150524, \\
20150528 \mathrm{~L}\end{array}$ & $\begin{array}{ll}20131117, & 20131118, \\
20131130, & 20131205, \\
20131208 \mathrm{a}, & 20131208 \mathrm{~b}, \\
20131208 \mathrm{c}, & 20131208 \mathrm{~d}, \\
20131209, & 20131210 \mathrm{a}, \\
20131210 \mathrm{~b}, & 20131212, \\
20131214, & 20131221, \\
20131227, & 20131228, \\
20140101, & 20140102, \\
20140114 \mathrm{a}, & 20140114 \mathrm{~b}, \\
20140114 \mathrm{c}, & 20140115, \\
20140118, & 20140129, \\
20140203, & 20140215, \\
20141201, & 20141203, \\
20141205, & 20141210, \\
20141220, & 20141222, \\
20141224 \mathrm{a}, & 20141224 \mathrm{~b}, \\
20141226, & 20151120, \\
20151123, & 20151128, \\
20151130, & 20151202, \\
20151212 \mathrm{a}, & 20151212 \mathrm{~b}, \\
20151213, & 20151214, \\
20151224 & \end{array}$ \\
\hline \# cases & 13 & 15 & 45 \\
\hline
\end{tabular}


Supplementary material to Subsection 2.2.3

Table S2. Landsat SIC using pixels only classified as thick ice derived using the actual pair of albedo threshold values ("Actual value") and the four variations of them (see text) averaged for 12 Landsat-8 scenes selected for the Northern Hemisphere (NH) at $25 \mathrm{~km}$ and $50 \mathrm{~km}$ grid resolution. The number to the right of the \pm denotes one standard deviation (supplements Table 3 in the main manuscript).

\begin{tabular}{|c|c|c|c|c|}
\hline$\alpha_{\text {thinice }} \backslash \alpha_{\text {openwater }}$ & -0.03 & Actual value & +0.03 & $\mathrm{NH}, 25 \mathrm{~km}$ \\
\hline-0.1 & $94.6 \pm 4.8$ & -- & $94.6 \pm 4.8$ & \\
\hline Actual value & -- & $93.2 \pm 4.7$ & -- & \\
\hline+0.1 & $90.8 \pm 4.4$ & -- & $90.8 \pm 4.4$ & \\
\hline & & & & $\mathrm{NH}, 50 \mathrm{~km}$ \\
\hline-0.1 & $94.3 \pm 5.5$ & -- & $94.3 \pm 5.5$ & \\
\hline Actual value & -- & $92.9 \pm 5.6$ & -- & \\
\hline+0.1 & $90.7 \pm 5.3$ & -- & $90.7 \pm 5.3$ & \\
\hline
\end{tabular}

Table S3. Landsat SIC using only pixels classified as thick ice derived using the actual pair of albedo threshold values ("Actual value") and the four variations of them (see text) averaged for 15 Landsat-8 scenes selected for the Southern Hemisphere (SH) at $25 \mathrm{~km}$ and $50 \mathrm{~km}$ grid resolution. The number to the right of the \pm denotes one standard deviation (supplements Table 4 in the main manuscript).

\begin{tabular}{|c|c|c|c|c|}
\hline$\alpha_{\text {thinice }} \backslash \alpha_{\text {openwater }}$ & -0.03 & Actual value & +0.03 & $\mathrm{SH}, 25 \mathrm{~km}$ \\
\hline-0.1 & $55.2 \pm 25.2$ & -- & $55.2 \pm 25.2$ & \\
\hline Actual value & -- & $52.6 \pm 24.9$ & -- & \\
\hline+0.1 & $49.9 \pm 24.8$ & -- & $49.9 \pm 24.8$ & \\
\hline & & & & $\mathrm{SH}, 50 \mathrm{~km}$ \\
\hline-0.1 & $47.7 \pm 31.1$ & -- & $47.7 \pm 31.1$ & \\
\hline Actual value & -- & $45.6 \pm 30.1$ & -- & \\
\hline+0.1 & $43.4 \pm 29.1$ & -- & $43.4 \pm 29.1$ & \\
\hline
\end{tabular}

\section{Supplementary material to Subsection 2.2.4}

We assume that a Landsat pixel $(30 \mathrm{~m} \times 30 \mathrm{~m})$ is completely covered by either ice or water. For a Landsat pixel covered just half by snow covered / thick sea ice, which exhibits a surface albedo of 0.8 under cold conditions, the resulting pixel average albedo is $0.5 \times 0.06+0.5 \times 0.8=0.43$. With that, the pixel is classified as bare / thin ice and counts as a pixel with $100 \%$ instead of $50 \%$ sea-ice concentration. Likewise, a pixel covered with $80 \%$ snow covered / thick sea ice with a similar surface albedo results in an average albedo of $0.2 \times 0.06+0.8 \times 0.8=0.65$. With that, the pixel is classified as snowcovered / thick ice and as well counts as a pixel with a sea-ice concentration of $100 \%$ instead of $80 \%$.

In order to assess the severity of this positive bias it is useful to distinguish between sea-ice conditions during summer and winter, in the pack ice and the marginal ice zone (MIZ), and to take into account different ice types as well as typical floe sizes. Regardless of ice type, floe size and location winter conditions are likely less prone to cause overly large biases in the Landsat SIC unless the sea ice drifts into open water regions with comparably high temperatures. Leads and openings in the pack ice are mostly frozen over. Only open ones, i.e. not covered by new or thin ice, would have an impact. Leads exhibiting widths below the Landsat pixel size of 30 meters would not be resolved as open water (see next paragraph). For wider open leads, the actual open water fraction would be smaller than the actual one because the mixed pixels at their borders would be classified at $100 \%$ sea ice.

Onana et al. (2013) analyzed airborne digital camera visible imagery captured along Operation Icebridge (OIB) flights in the Arctic in April and in the Antarctic in October at $\sim 0.1 \mathrm{~m}$ nadir spatial resolution for the lead and open water fraction along the flight tracks; their lengths were $\sim 7000 \mathrm{~km}$ in the Antarctic and $\sim 5300 \mathrm{~km}$ in the Arctic. They reported an open water 
fraction of $\sim 1.2 \%$ for the Antarctic flight and of $\sim 0.2 \%$ for the Arctic flight. The spatial resolution of their input data of 0.1 $\mathrm{m}$ allows to reliably detect $1 \mathrm{~m}$-wide leads. These are clearly sub-resolution for Landsat. Lead width distributions follow a power law with lead counts decreasing with increasing lead width (e.g. Tschudi et al., 2002; Marcq and Weiss, 2012). Therefore, it can be expected that only comparably few leads along these OIB flight tracks exhibit an open water signature wide enough to also be identified by Landsat as open water at $30 \mathrm{~m}$ pixel size; the bulk of the open water in small-scale leads remains undetected. With that Landsat SIC is biased high simply because of the "coarse" resolution of the Landsat sensor but the magnitude of this bias (unknown but smaller than the two above-mentioned percentage values) falls within the uncertainty range of our approach (Subsection 2.2.3; Tables 3 and 4). For leads wider than $30 \mathrm{~m}$, we can attempt to estimate the contribution of mixed pixels classified as ice, i.e. the pixels at the lead boundaries, on the Landsat SIC at, for instance, $25 \mathrm{~km}$ grid resolution. Into one $25 \mathrm{~km}$ x $25 \mathrm{~km}$ grid cell 694444 Landsat pixels fit. Let us assume there is some land so that the actual ice-covered ocean area comprises 500000 pixels. An open water fraction (see above) of $\sim 1 \%$ corresponds to 5000 pixels. Landsat cannot resolve all of these because the bulk of the $1 \%$ open water fraction is from sub-pixel size leads. If we assume that Landsat can identify half of that open water fraction then we are at 2500 pixels. Of these 2500 pixels two third, i.e. $\sim 1600$ might actually be pixels at lead boundaries, hence classified as $100 \%$ ice instead of some fraction between $0 \%$ and $100 \%$. When related to the entire $25 \mathrm{~km}$ grid cell and assuming that the average ice fraction of the misclassified pixels is $50 \%$, these 1600 pixels correspond to an over-estimation of the SIC by $\sim 0.15 \%$. This value falls into the uncertainty range of our approach (Subsection 2.2.3; Tables 3 and 4). We note that these considerations rely on the assumption that the OIB flights provide a representative estimate of the conditions of Arctic and Antarctic pack ice during winter conditions.

We also estimated the bias for three typical airborne visible images taken in the MIZ in the Greenland Sea, Arctic, during winter in March 1997 (http://seaice.dk/esop/egr197/, last access July 2 2021). The images show a sea-ice cover comprising closely packed but also broken bands of thicker ice floes, pancake ice, brash and grease ice; the approximate seaice concentration is around $70 \%$. We superpose the images, which are approximately $4 \mathrm{~km}$ wide, with a grid representing the Landsat pixel size of $30 \mathrm{~m}$ x $30 \mathrm{~m}$, and visually count the mixed pixels that exhibit a non-zero open water fraction of approximately more than $\sim 5 \%$. The number of usable pixels of the 12060 pixels in total ranges between 10532 and 11205 because some were obscured by parts of the aircraft and other remote sensing equipment in the field of view of the camera used. We find between 908 and 2057 mixed pixels, corresponding to a fraction between $8.1 \%$ and $19.2 \%$. If we translate this situation to a $25 \mathrm{~km}$ grid cell, then our approach would result in between $8.1 \%$ and $19.2 \%$ of the Landsat pixels in that grid cell classified as $100 \%$ ice instead of some fraction between $5 \%$ and $100 \%$. By assuming that the ice fraction in these pixels is, on average, $50 \%$, we can estimate an overall positive bias in the Landsat SIC of between $\sim 4 \%$ and $\sim 10 \%$ for the ice conditions encountered.

During summer, the thin ice detected by Onana et al. (2013) along the above-mentioned OIB flights would be open water; the corresponding open water fraction would be $5.5 \%$ for the Antarctic flight and $1.5 \%$ for the Arctic flight. We can expect that Landsat would identify only a comparably small part of these open water patches because of the reasons laid out earlier, leading to Landsat SIC biased high simply due to the resolution. In addition, mixed pixels at the lead boundaries classified as $100 \%$ ice would lead to an elevated positive bias. We can repeat the earlier exercise and provide an estimate of the impact of these mixed pixels. For that we replace the values of the open water fraction of $\sim 1 \%$ by $\sim 5 \%$. Note that we take the Antarctic example here because only in the Antarctic we work with summer-time Landsat scenes. For the conditions chosen, i.e. $\sim 5 \%$ open water fraction, the bias due to mixed pixels would then be the five-fold value of the above-mentioned one: $\sim 0.75 \%$. We now could expand this examination to even larger open water fractions. However, it is not clear whether it is justified to linearly increase the value of the potential mixed-pixel bias as a function of the open water fraction, i.e. whether this bias would amount, e.g., $1.5 \%$ for an open water fraction of $10 \%$ and $3 \%$ for an open water fraction of $20 \%$. We attempt to shed light on this issue in the following paragraphs. 
A sea-ice cover comprises a mélange of individual ice floes that are frozen together in winter but are often floating individually, only "glued" together by slush and brash ice formed from disintegrating floes or ridges in summer. Like the lead width distribution does also the floe size distribution follow a power law with maximum floe count for small floes, decreasing to smaller counts for larger floes (e.g. Steer et al., 2008; Toyota et al., 2011; Perovich and Jones, 2014). Depending on season and location also the floe size could cause biases in Landsat SIC estimates based on our approach - primarily because of two reasons. At first, a considerable fraction of the ice floes encountered in the MIZ, particularly in the Antarctic, exhibit sizes smaller than the Landsat pixel size of $30 \mathrm{~m}$ (Lu et al., 2008; Steer et al., 2008; Toyota et al., 2011; 2016). According to our first paragraph of Subsection 2.2.4 in the main manuscript, one snow-covered ice floe of $\sim 6 \mathrm{~m}$ size would be enough to increase the pixel average albedo above the upper open water / ice discrimination threshold of 0.09 (see Tables 3 and 4 ) and to classify that pixel as ice. One ice floe of that size corresponds to a sea-ice concentration of $\sim 4 \%$ in that pixel. For an ice floe with melting snow, bare ice or any form of thin ice without a snow cover the floe size needs to be larger to cross that threshold; i.e. for thin ice with a surface albedo of 0.35 the floe could be $10 \mathrm{~m}$ in size, corresponding to a sea-ice concentration of $\sim 11 \%$ in that pixel. In both cases, the classification results in a pixel with $100 \%$ SIC. A $25 \mathrm{~km}$ grid cell comprising such Landsat pixels would exhibit an extremely overestimated Landsat SIC value. Secondly, for floes larger than the Landsat pixel size, each floe boundary intersecting with a pixel produces a mixed Landsat pixel. Hence, one isolated ice floe of, for instance, $\sim 50 \mathrm{~m}$ diameter could, in the worst case, fill one Landsat pixel completely and overlap with the eight surrounding Landsat pixels as well. As a result, nine Landsat pixels would be classified as ice, i.e. $8100 \mathrm{~m}^{2}$ while the actual area of the floe, if assumed to be a circular disc, would be $\sim 2000 \mathrm{~m}^{2}$; this is a four-fold overestimation of the actual sea-ice area.

However, as we state at the beginning of the previous paragraph, the sea-ice cover is a mixture of ice floes of difference sizes and shapes. During winter, any openings between floes are small and/or frozen; floe size distributions and the two issues mentioned above do not have a notable impact on the Landsat SIC at the scale of the PMW SIC product grid resolution - particularly not in the Arctic Ocean (Perovich and Jones, 2014). During summer, the type of ice cover in the openings is more difficult to assess and to take into account in a quantitative way. According to the high-resolution optical images shown in the publications used to infer the floe size distribution (Steer et al., 2008; Toyota et al., 2011; 2016) and similar studies (e.g. Paget et al., 2001; Lu et al., 2008; Zhang and Skjetne, 2015), the ice cover often comprises a large spectrum of floes. Small floes float in openings between moderately large floes that in turn float in openings between large floes. In addition, slush and/or brash ice often fills the remaining gaps. Therefore, for these cases the actual sea-ice concentration is close to $100 \%$ and would also be close to $100 \%$ following our classification method despite the substantial variation in surface albedo due to the mixture of different ice types.

There are, however, cases where both, floe size and size of the openings between the floes are smaller than the Landsat pixel size and where in addition the openings are not covered by brash ice or slush, examples of which are shown, e.g., in Toyota et al. (2011). For these cases, certainly too many Landsat pixels would be classified as $100 \%$ ice and the Landsat SIC would be biased high at the scale of the PMW SIC product grid resolution. Herding of ice floes under the action of wind waves and swell can generate larger conglomerates of densely packed floes separated by larger, lead-like openings (Toyota et al., 2016). The process decreases the amount of isolated sub-pixel scale floes and openings and potentially results in a smaller positive bias. In the following, we attempt to estimate the efficiency of this herding. We assume two $25 \mathrm{~km}$ grid cells, A and $\mathrm{B}$, in the open ocean, i.e. no land, with an actual sea-ice concentration of $50 \%$. Grid cell A is covered completely by isolated floes with a size smaller than the Landsat pixel size, separated by open water patches of the same size. This is a very extreme, unlikely situation at a scale of $25 \mathrm{~km}$ squared. With our approach, we would classify every pixel as $100 \%$ ice and the resulting $25 \mathrm{~km}$ grid cell Landsat SIC would be $100 \%$. Grid cell B is covered by ten parallel bands of herding-induced closely-packed ice floes with near-100\% SIC separated by open water bands (wide leads). A good estimate for the length of these bands is 1000 Landsat pixels. While our approach would do fine for the near-100\% sea ice band and the pure open water pixels in the wide leads, the mixed pixels at the wide lead boundaries cause a positive bias - as described already above. Ten wide leads 
with two borders on each side estimate to $20 \times 1000=20000$ Landsat pixels with a mixed surface that would be classified as $100 \%$ ice instead the actual ice fraction between $0 \%$ and $100 \%$. This amounts to $\sim 3 \%$ of the pixels in grid cell B, translating into an over-estimation of the SIC by $\sim 1.5 \%$ under the assumption that the average actual ice fraction in the misclassified pixels is again $50 \%$. Hence, for grid cell A, Landsat SIC is $100 \%$ instead of $50 \%$ while for grid cell B Landsat SIC is $~ 52$ $\%$ instead of $50 \%$. This example illustrates that for our approach there is a large range of Landsat SIC overestimation at PMW SIC product grid resolutions for those summer ice conditions where gaps between ice floes are not filled by slush, brash ice or young ice types.

A special ice form not yet treated is pancake ice. This ice type forms predominantly at the ice edge / in the MIZ from grease and slush ice under the action of wind and waves. Floe sizes of pancake ice are small, mostly below 10 meters. Despite this, we are confident Landsat SIC match the actual sea-ice concentration in pancake ice regions well because of several reasons. Such regions occur during winter conditions and therefore any sub-pixel scale open water fractions are very low. Pancake ice floes are often embedded into a matrix of grease and slush ice, both exhibiting an albedo above the open water ice discrimination threshold used. Actual sea-ice area fractions in pancake ice dominated areas are often near $100 \%$ according to visual ship-based sea ice observations (e.g. Ozsoy-Cicek et al., 2011; Alberello et al., 2019). Only at the border of pancake ice regions that often occur in bands an over-estimation of the Landsat SIC due to the above-described mixed-pixel effect is possible. This effect is more difficult to quantify as in case of the leads (see above) but we doubt that the resulting bias would exceed $2 \%$ at the $25 \mathrm{~km}$ scale of the PMW SIC grid - unless the ice is advected into warmer waters inhibiting ice formation; then biases could be as large as $10 \%$.

One way to reduce the unknown bias in the used Landsat SIC estimates could be to switch from the binary classification, i.e. water or ice, to an estimation of the actual SIC in every pixel as a function of the albedo, i.e. a gradient approach (see e.g. Kern et al., 2003). That way one would have $0 \%$ SIC for pixels with a typical open water albedo, $50 \%$ SIC for pixels with an albedo of, e.g. 0.4 , and $100 \%$ SIC for pixels with an albedo of 0.8 . This is, however, an over-simplification of the situation as well because an albedo of 0.4 might indeed originate from a pixel with $50 \%$ SIC but it might as well originate from a pixel covered by $100 \%$ thin ice. Hence, such a gradient approach would result in an unknown amount of under-estimation of the Landsat SIC in some grid cells. One solution to avoid this negative bias could be to use the albedo of a pixel covered by $100 \%$ thin ice, e.g. 0.4 or similar, as the end-member of the gradient approach, i.e. all pixels with an albedo $>0.4$ are set to $100 \%$ SIC while intermediate SIC is estimated for pixels exhibiting smaller albedo values. However, in order to generate such a high-quality Landsat SIC data set one needs a more accurate correction of the atmospheric influence, and consideration of sun elevation and observation angles than employed in this study. In addition, also here an independent data set of an even finer-resolved ice-water distribution is required to assess the quality.

\section{Additional References:}

Alberello, A., Onorato, M., Bennetts, L., Vichi, M., Eayrs, C., MacHutchon, K., and Toffoli, A.: Pancake ice floe size distribution during the winter expansion of the Antarctic marginal ice zone. The Cryosphere, 13(1), 41-48, https://doi.org/10.5194/tc-13-41-2019, 2019.

Kern, S., Kaleschke, L., and Clausi, D. A.: A comparison of two 85-GHz SSM/I ice concentration algorithms with AVHRR and ERS-2 SAR imagery. IEEE Trans. Geosci. Rem. Sens., 41(10), 2294-2306, https://doi.org/10.1109/TGRS.2003.817181, 2003.

Ozsoy-Cicek, B., Kern, S., Ackley, S. F., Xie, H., and Tekeli, A. E.: Intercomparisons of Antarctic sea ice types from visual ship, RADARSAT-1 SAR, Envisat ASAR, QuikSCAT, and AMSR-E satellite observations in the Bellingshausen Sea, Deep-Sea Res. II, 58(9-10), 1092-1111, https://doi.org/10.1016/j.dsr2.2010.10.031, 2011. 

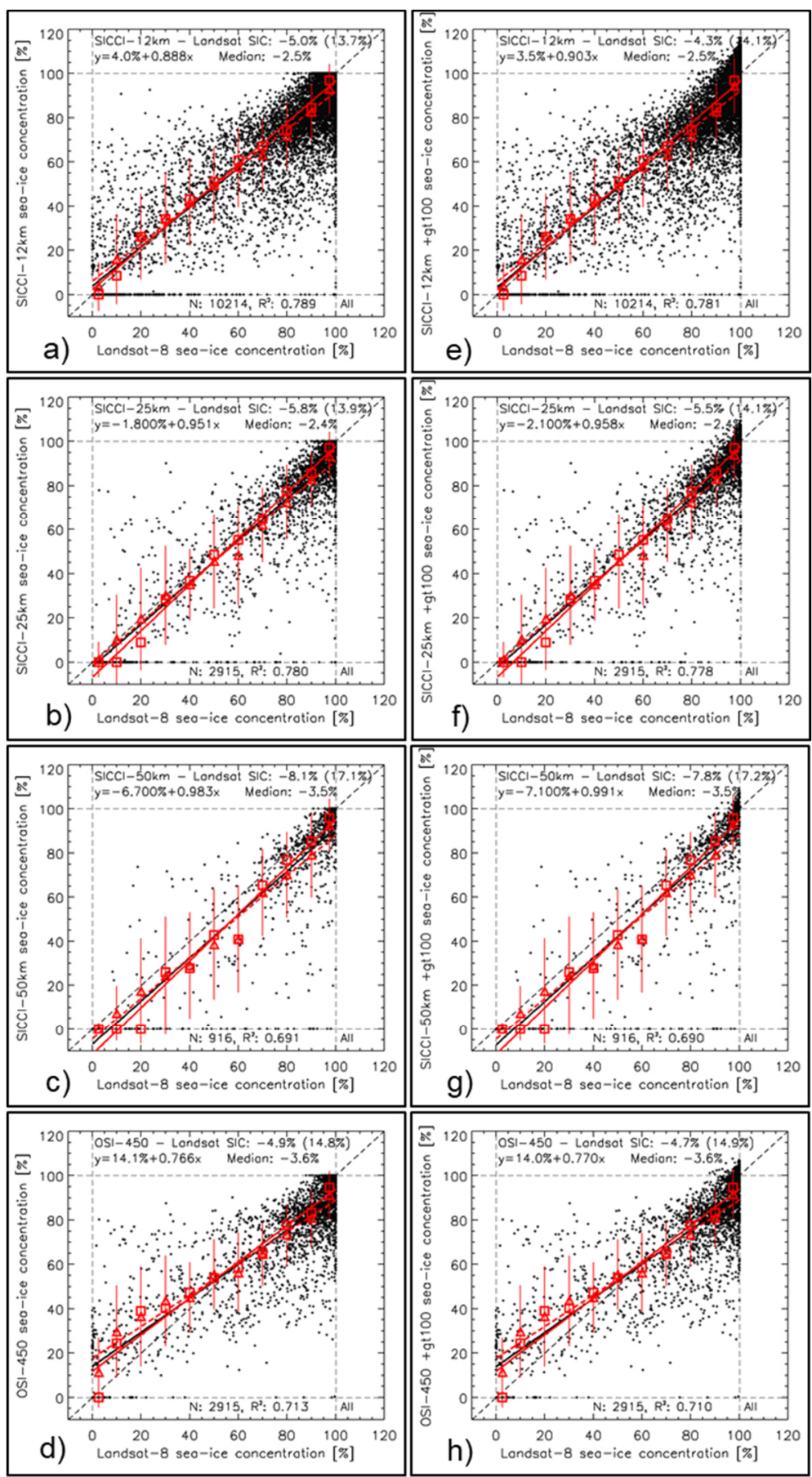

truncated

non-truncated

Figure S1. Scatterplots of PMW SIC (y-axis) versus Landsat SIC (x-axis) for SICCI-2 and OSI-450 products for Landsat-8 melt conditions cases during years 2013-2015 in the Southern Hemisphere. Black dots are individual data pairs, the black solid line is the linear regression, and the black dashed line is the identity line. Red triangles denote the mean PMW SIC computed for Landsat SIC ranges 0\%-5\%, 5\%-15\%, 15\%-25\%, ., 85\%-95\%, 95\%-100\%, red bars one standard deviation of these mean values, and the red dashed line is the respective linear regression line. Red squares denote the median PMW SIC of the same Landsat SIC ranges, and the red solid line is the respective linear regression line. The overall mean and median difference 
PMW SIC minus Landsat SIC, its standard deviation, and the equation of the linear regression through the individual data pairs is given at the top, the number $\mathrm{N}$ of data pairs and the squared linear correlation coefficient at the bottom of each panel.
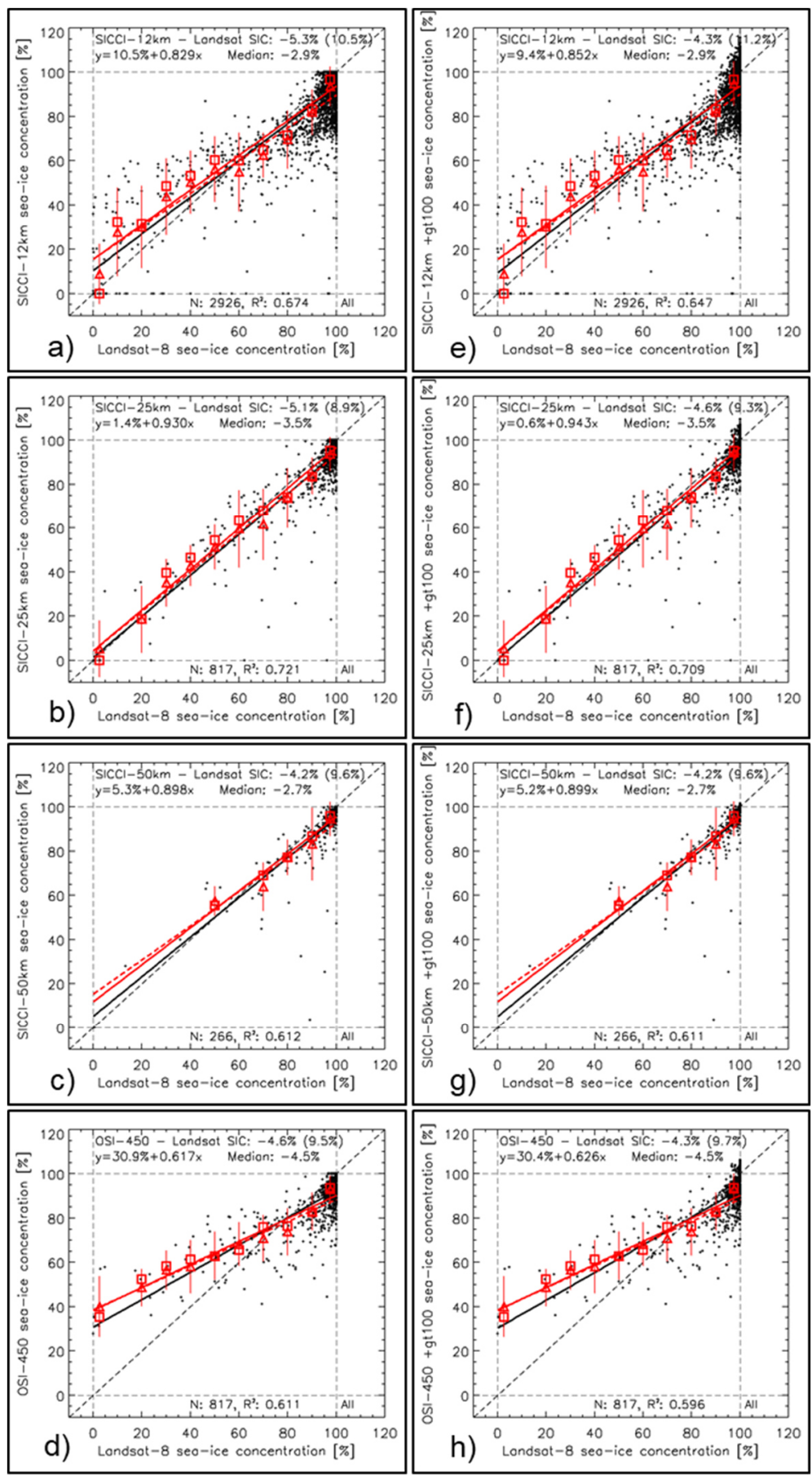

truncated

non-truncated

Figure S2. Same as Fig. S1 but for the Northern Hemisphere. 

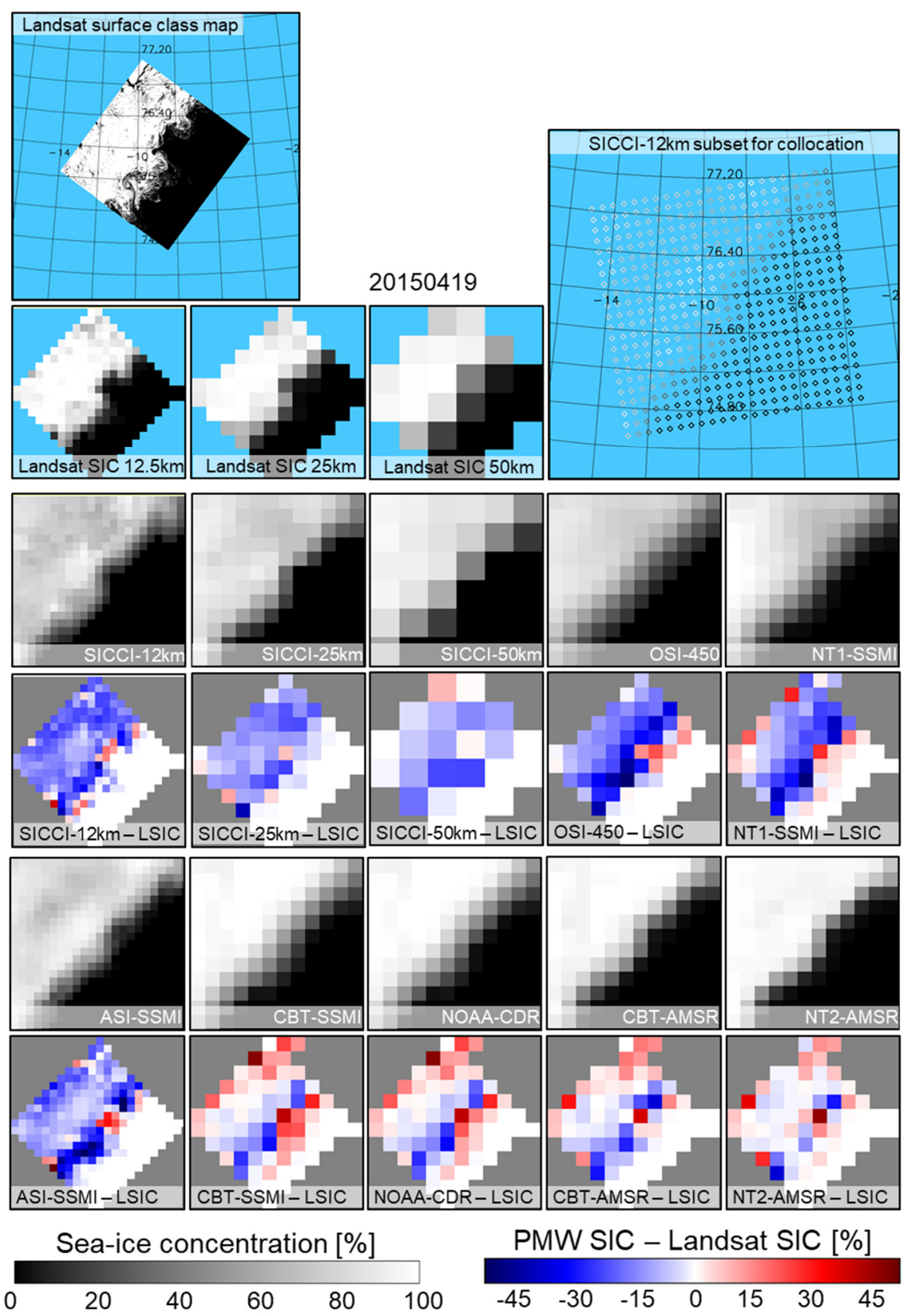

Figure S3. Landsat-8 SIC, PMW SIC, and difference PMW SIC minus Landsat SIC (LSIC) for all ten products for an ice egde scene in the Fram Strait on April 19, 2015. The Landsat surface class map (top left) shows white: thick/snow covered ice; grey: thin/new bare ice; black: open water). White and grey pixels are used to compute maps of LSIC at $12.5 \mathrm{~km}, 25 \mathrm{~km}$ and $50 \mathrm{~km}$, respectively (blue: outside Landsat image). A subset of SICCI-12km SIC grid cells shown (top right) illustrates the array used for the collocation. Panels in the remaining four rows below show PMW SIC and PMW SIC minus LSIC. Land is flagged brown in the SIC panels and black in the SIC difference panels; it differs between the PMW products. Land masks in the two bigger maps are from the plotting routine and differ from the land masks of the PMW SIC products. LSIC uses land masks of the SICCI-2 products. 


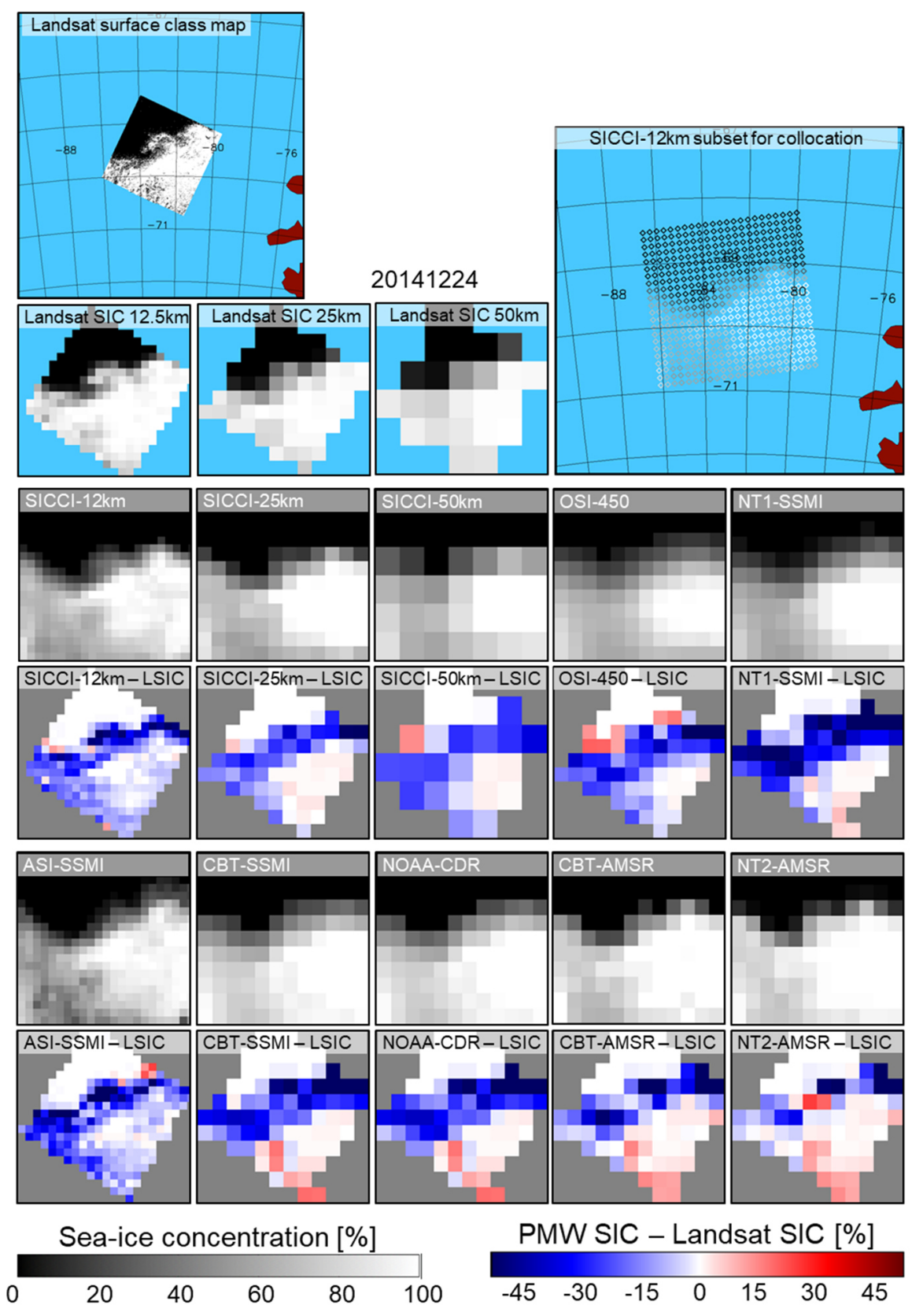

Figure S4. Landsat-8 SIC, PMW SIC, and difference PMW SIC minus Landsat SIC for all ten products for an ice edge scene in the Bellingshausen Sea, Southern Ocean, on December 24, 2014. See Fig. S3 for a description of the maps shown. This scene also falls into the set of scenes selected for melt conditions because it is from December. 

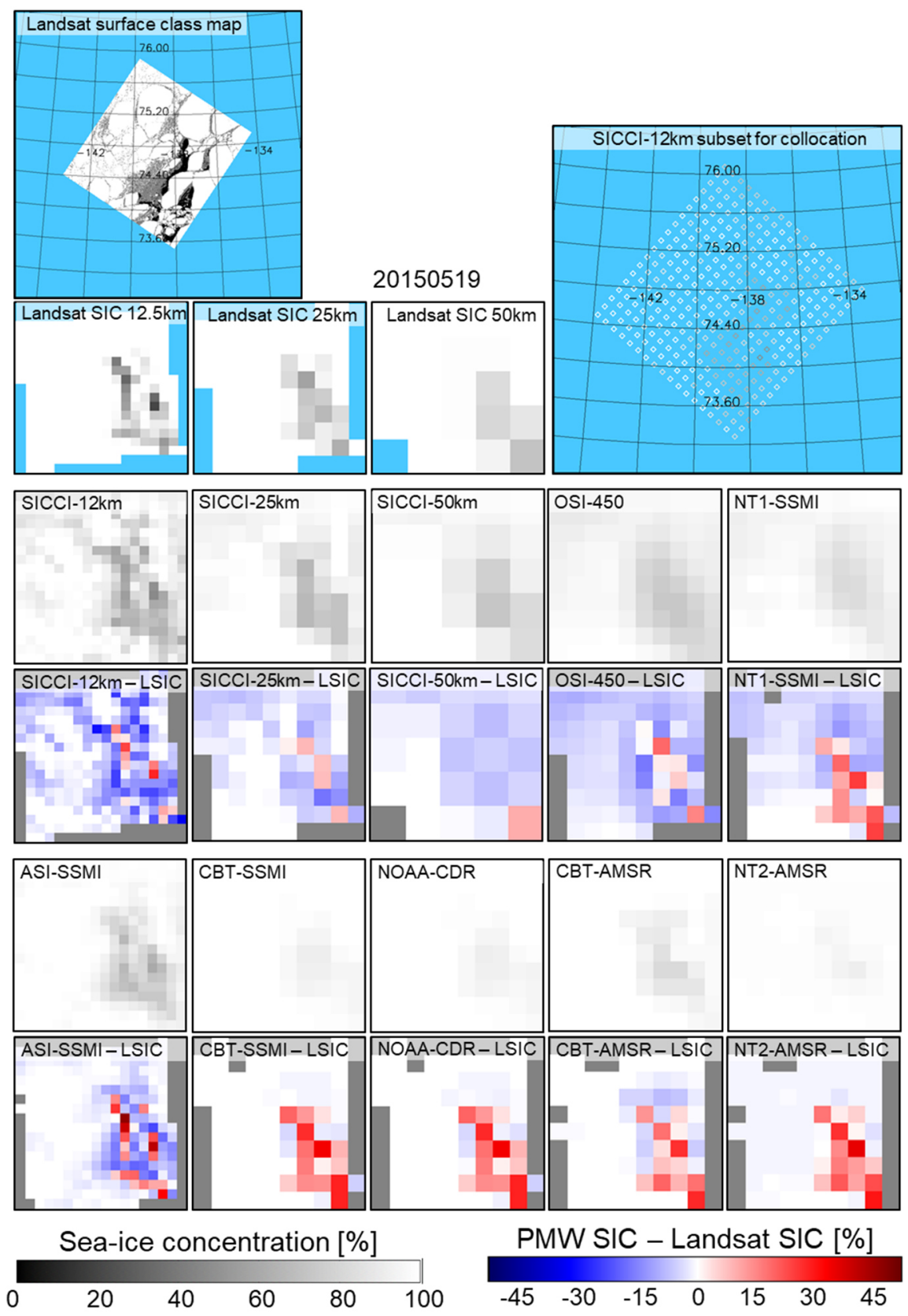

Figure S5. Landsat-8 SIC, PMW SIC, and difference PMW SIC minus Landsat SIC for all ten products for a heterogeneous ice conditions scene (openings in multiyear pack ice) in the Beaufort Sea, Arctic Ocean, on May 19, 2015. See Fig. S3 for a description of the maps shown. This scene also falls into the set of scenes selected for melt conditions because it is from the second half of May. 


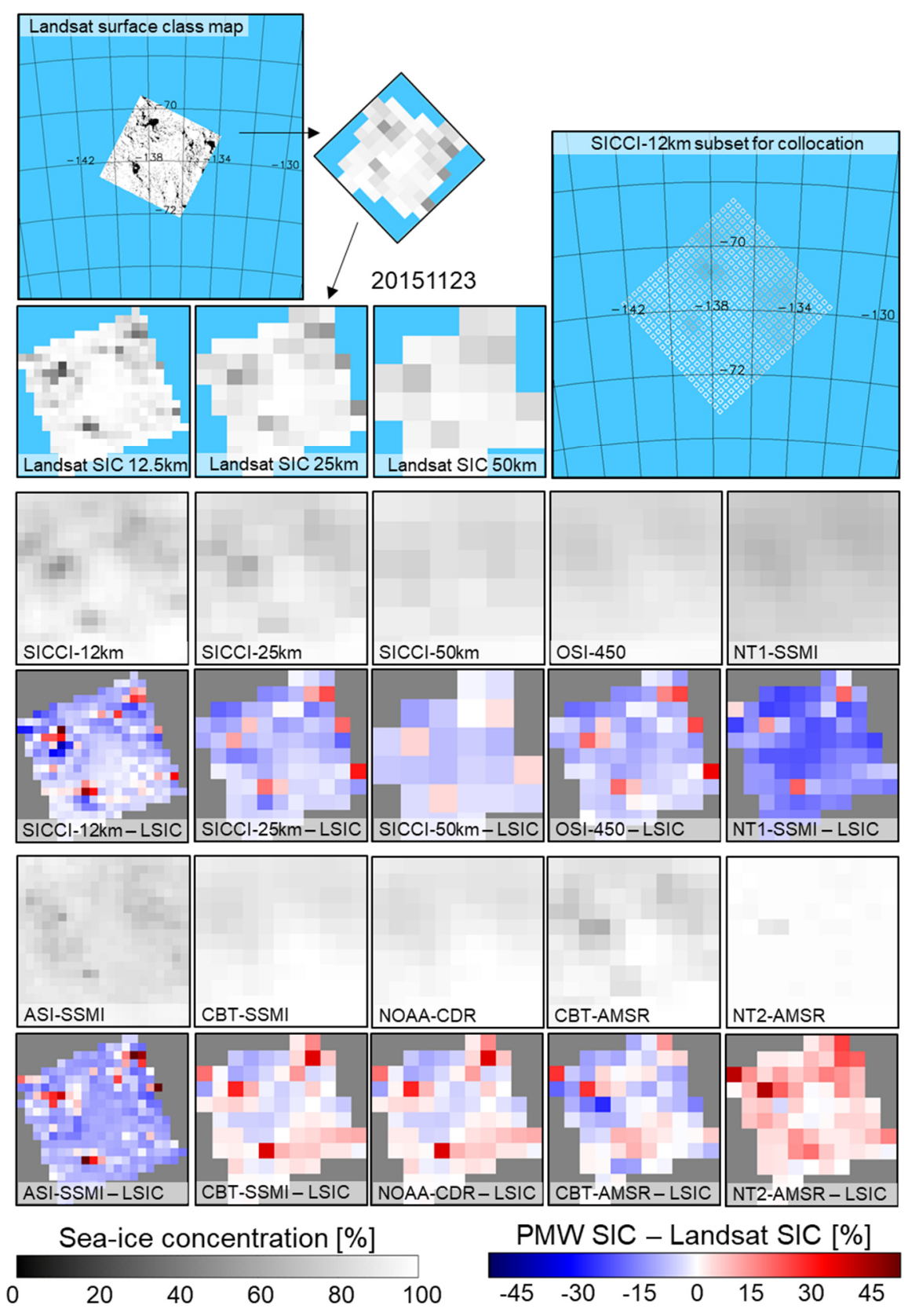

Figure S6. Landsat-8 SIC, PMW SIC, and difference PMW SIC minus Landsat SIC for all ten products for a heterogeneous ice conditions scene in the Ross Sea, Southern Ocean, on November 23, 2015. See Fig. S3 for a description of the maps shown. This scene also falls into the set of scenes selected for melt conditions because it is from the second half of November. 

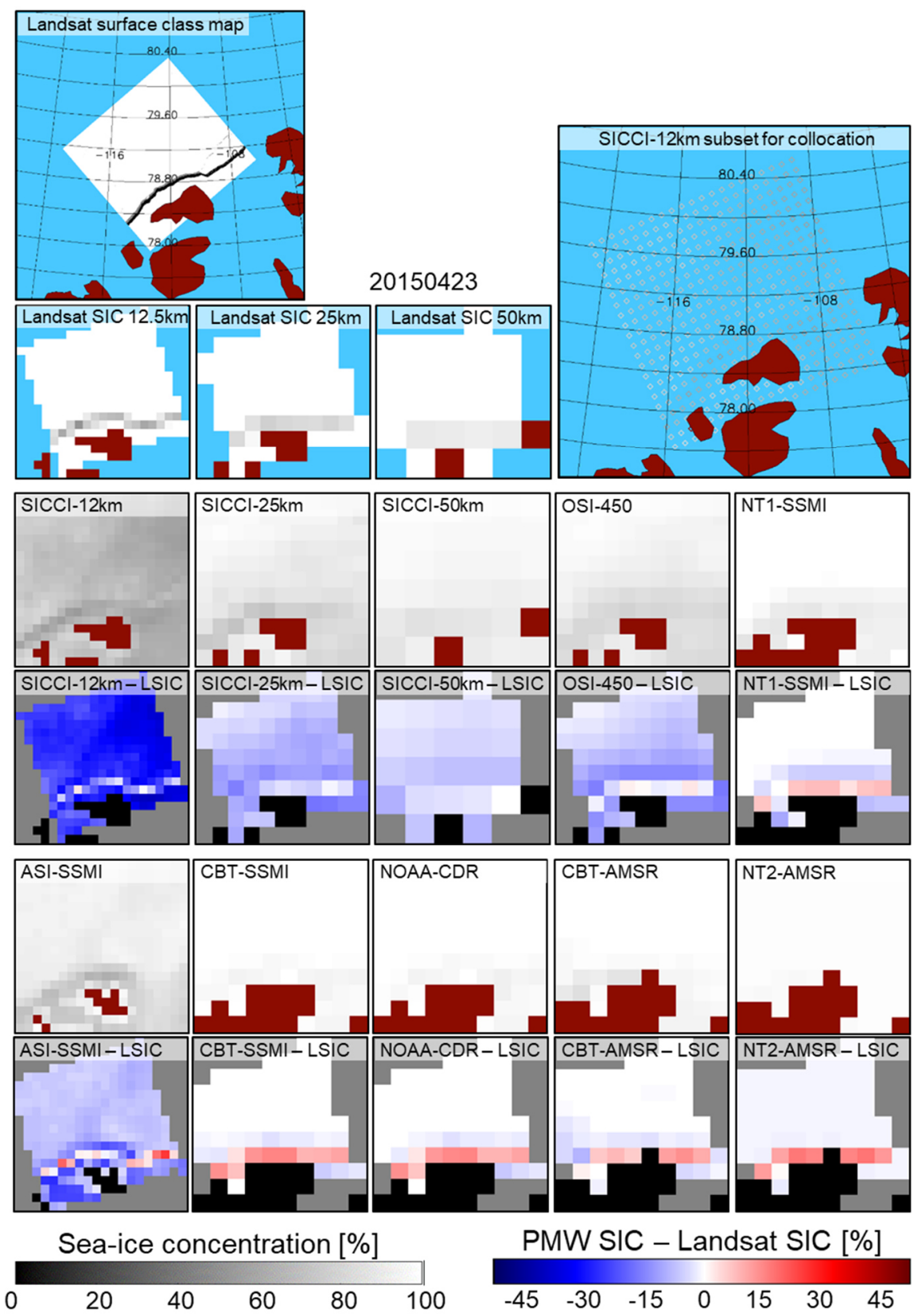

Figure S7. Landsat-8 SIC, PMW SIC, and difference PMW SIC minus Landsat SIC for all ten products for a lead / openings scene north of Franz-Joseph Land, Arctic Ocean, on April 23, 2015. See Fig. S3 for a description of the maps shown. 


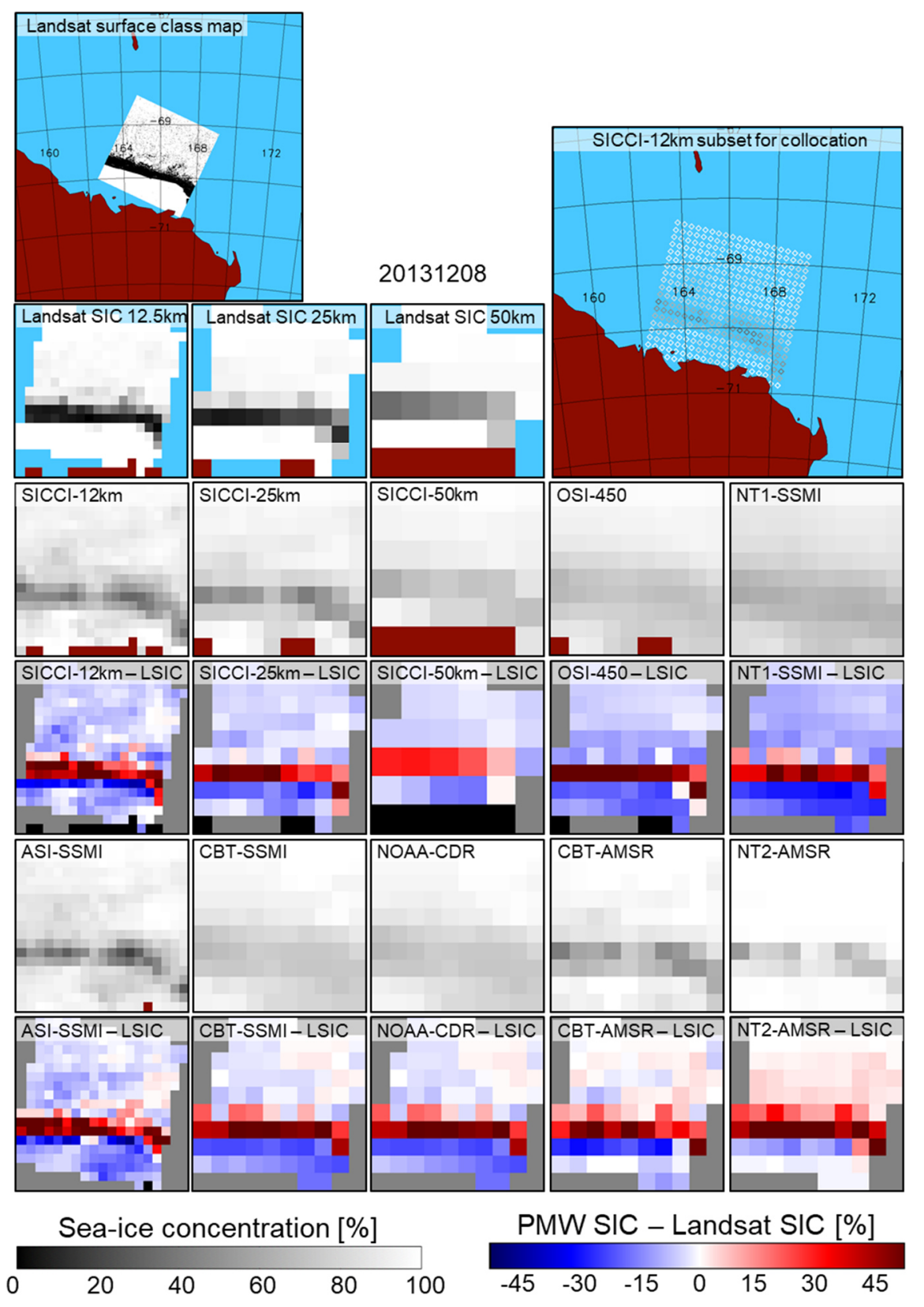

Figure S8. Landsat-8 SIC, PMW SIC, and difference PMW SIC minus Landsat SIC for all ten products for a lead / openings scene in the Ross Sea, Southern Ocean, on December 8, 2013. See Fig. S3 for a description of the maps shown. This scene also falls into the set of scenes selected for melt conditions because it is from December. 
Table S4. Comparison of statistical parameters as listed in Table 8 in the main manuscript but for different sets of filters (see Subsection 5.3) for the Northern Hemisphere for SICCI-2 and OSI-450 products and Landsat-8. Shown are values for settings "fully truncated": the main SIC product with all filters applied, "GT100 off": only the truncation at near-100\% SIC is switched off (this corresponds "non-truncated" as used throughout the paper), "GT100 / OWF off": near-100\% SIC and OWF are switched off, "GT100 / LSO off": near-100\% SIC and LSO switched off, and "Fully non-truncated": no filters applied, all SIC estimates as retrieved by the algorithms are used.

\begin{tabular}{|l|c|c|c|c|c|}
\hline LS8, NH 2013-15 & Diff & DiffSDEV & Slope & Intercept & $\mathrm{R}^{2}$ \\
\hline SICCI-12km & \multicolumn{5}{|l|}{} \\
\hline Fully truncated & -6.2 & 11.0 & 0.868 & 6.1 & 0.72 \\
\hline GT100 off & -4.9 & 12.1 & 0.891 & 5.2 & 0.68 \\
\hline GT100 / OWF off & -4.8 & 12.2 & 0.872 & 7.1 & 0.68 \\
\hline GT100 / LSO off & -4.7 & 11.9 & 0.872 & 7.1 & 0.69 \\
\hline Fully non-truncated & -4.6 & 11.9 & 0.853 & 9.0 & 0.68 \\
\hline SICCI-25 & \multicolumn{5}{|l|}{} \\
\hline Fully truncated & -4.7 & 8.2 & 0.974 & -2.4 & 0.84 \\
\hline GT100 off & -4.4 & 8.5 & 0.982 & -2.7 & 0.83 \\
\hline GT100 / OWF off & -4.3 & 8.5 & 0.962 & -0.7 & 0.82 \\
\hline GT100 / LSO off & -4.0 & 7.8 & 0.934 & 2.1 & 0.84 \\
\hline Fully non-truncated & -3.9 & 7.8 & 0.914 & 4.1 & 0.84 \\
\hline SICCI-50 & \multicolumn{5}{|l|}{} \\
\hline Fully truncated & -3.6 & 9.0 & 0.997 & -3.3 & 0.79 \\
\hline GT100 off & -3.4 & 9.1 & 1.000 & -3.5 & 0.79 \\
\hline GT100 / OWF off & -3.3 & 9.0 & 0.968 & -0.4 & 0.78 \\
\hline GT100 / LSO off & -2.8 & 7.1 & 0.943 & 2.5 & 0.85 \\
\hline Fully non-truncated & -2.6 & 7.0 & 0.911 & 5.7 & 0.84 \\
\hline OSI-450 & -4.3 & 9.8 & 0.779 & 16.2 & 0.73 \\
\hline Fully truncated & -3.9 & 9.9 & 0.786 & 15.9 & 0.73 \\
\hline GT100 off & -3.9 & 10.0 & 0.775 & 16.9 & 0.72 \\
\hline GT100 / OWF off & -3.9 & 10.0 & 0.782 & 16.3 & 0.72 \\
\hline GT100 / LSO off & -3.9 & 10.0 & 0.771 & 17.3 & 0.72 \\
\hline Fully non-truncated
\end{tabular}


Table S5. As Table S4 but for the Southern Hemisphere.

\begin{tabular}{|l|c|c|c|c|c|}
\hline LS8, SH 2013-15 & Diff & DiffSDEV & Slope & Intercept & $\mathrm{R}^{2}$ \\
\hline SICCI-12km & \multicolumn{5}{|l|}{} \\
\hline Fully truncated & -5.3 & 13.3 & 0.915 & 2.1 & 0.78 \\
\hline GT100 off & -4.3 & 13.8 & 0.931 & 1.6 & 0.77 \\
\hline GT100 / OWF off & -4.1 & 13.7 & 0.912 & 3.4 & 0.77 \\
\hline GT100 / LSO off & -4.1 & 13.3 & 0.921 & 2.7 & 0.78 \\
\hline Fully non-truncated & -3.9 & 13.2 & 0.903 & 4.5 & 0.78 \\
\hline SICCI-25 & -5.9 & 13.7 & 0.969 & -3.3 & 0.77 \\
\hline Fully truncated & -5.6 & 13.7 & 0.976 & -3.5 & 0.77 \\
\hline GT100 off & -5.6 & 0.959 & -1.9 & 0.76 \\
\hline GT100 / OWF off & -5.4 & 13.6 & 0.952 & -0.6 & 0.81 \\
\hline GT100 / LSO off & -4.7 & 11.9 & 0.935 & 1.1 & 0.81 \\
\hline Fully non-truncated & -4.5 & 11.2 & & \\
\hline SICCI-50 & \multicolumn{5}{|l|}{} \\
\hline Fully truncated & -6.8 & 16.0 & 1.033 & -9.6 & 0.72 \\
\hline GT100 off & -6.5 & 16.2 & 1.040 & -9.9 & 0.71 \\
\hline GT100 / OWF off & -6.0 & 16.0 & 0.988 & -5.0 & 0.70 \\
\hline GT100 / LSO off & -3.9 & 11.5 & 0.953 & 0.1 & 0.81 \\
\hline Fully non-truncated & -3.4 & 11.1 & 0.902 & 5.0 & 0.81 \\
\hline OSI-450 & -5.3 & 13.5 & 0.827 & 9.5 & 0.73 \\
\hline Fully truncated & -5.1 & 13.7 & 0.832 & 9.3 & 0.73 \\
\hline GT100 off & -5.0 & 13.7 & 0.816 & 10.8 & 0.72 \\
\hline GT100 / OWF off & -4.9 & 13.5 & 0.818 & 10.7 & 0.73 \\
\hline GT100 / LSO off & -4.8 & 14.2 & 0.802 & 12.2 & 0.73 \\
\hline Fully non-truncated
\end{tabular}

